\title{
A Study on Variations of Nutrient Foramen of Humerus in Kurnool, Andhra Pradesh, India, and Its Clinical Relevance
}

\author{
Govula Subramanyam¹ ${ }^{1}$ Kategari Chittinarasamma르. Chaluvadi Jayamma ${ }^{3}$, R. Somasekhar ${ }^{4}$ \\ 1, 2, 3,4 Department of Anatomy, Kurnool Medical College, Kurnool, Andhra Pradesh, India.
}

\section{ABSTRACT}

\section{BACKGROUND}

Nutrient foramen of humerus is an opening in the shaft of humerus which conducts nutrient vessels for medullary cavity. Major source of blood supply to long bone is the nutrient artery. Knowledge regarding nutrient foramen is important for orthopaedic surgeons while doing any procedure on humerus like bone grafting, plating and also plays an important role in fracture healing. We wanted to determine the location, number, and direction of nutrient foramen of humerus.

\section{METHODS}

The observational study was conducted on 72 adult humeri (36 of right side and 36 of left side) collected from Department of Anatomy, Kurnool Medical College, Kurnool, Andhra Pradesh from 15 ${ }^{\text {th }}$ September to 31st October 2020. Each humerus was observed for location, number, and direction of nutrient foramen in relation with surface, border and zone.

\section{RESULTS}

In the present study it has been observed that $61 \%$ of humeri had a single foramen, $31 \%$ had two foramina and $8 \%$ had 3 foramina. Majority of nutrient foramina (54.95 \%) were present on antero-medial surface, $12.08 \%$ on anterolateral surface, $12.08 \%$ on posterior surface, $19.78 \%$ on medial border, and 1.09 $\%$ on lateral border. It was also concluded that most $(94.50 \%)$ of the foramina were present in the zone II followed by zone III (3.30 \%) then by zone I (2.19\%).

\section{CONCLUSIONS}

Knowledge of number and location of the nutrient foramina in humerus will be helpful in preventing intra-operative injury of nutrient artery during orthopaedic, plastic and reconstructive surgery; and will also be relevant in medico legal practice.

\section{KEY WORDS}

Nutrient Foramen, Humerus, Nutrient Artery, Foraminal Index, Clinical Implications
Corresponding Author: Dr. K. Chittinarasamma, MS Professor and Head of the Department, Department of Anatomy Kurnool Medical College, Kurnool, Andhra Pradesh, India. E-mail: chittynarasamma.k@gmail.com

DOI: $10.14260 /$ jemds/2021/366

How to Cite This Article:

Subramanyam G, Chittinarasamma $K$, Jayamma $C$, et al. A study on variations of nutrient foramen of humerus in Kurnool, Andhra Pradesh, India, and Its clinical relevance. J Evolution Med Dent Sci 2021;10(23):1772-1776, $10.14260 /$ jemds $/ 2021 / 366$

Submission 04-11-2020,

Peer Review 14-04-2021,

Acceptance 20-04-2021,

Published 07-06-2021.

Copyright (C) 2021 Govula Subramanyam et al. This is an open access article distributed under Creative Commons Attribution License [Attribution 4.0 International (CC BY 4.0)] 


\section{BACKGROUND}

Nutrient foramen of Humerus is an opening into the shaft of the humerus bone. Its direction is oblique nutrient canal passing through cortex and ultimately opens into the medullary cavity. The nutrient artery enters into the medullary cavity through nutrient foramen and the canal which is a rich source of blood supply to the medullary cavity and inner two-third of cortex of the humerus. The nutrient blood supply is crucial for any long bones and it should be preserved in order to promote the fracture healing. ${ }^{1}$ Moreover, for the survival of the osteocytes in cases of tumour resection, trauma, and congenital pseudoarthrosis. ${ }^{2}$ the presence of preserved nutrient blood supply is essential. Nutrient Foramen is usually single in number and located on the antero-medial surface of the humerus a little below its midpoint close to the medial border. It is usually directed toward the lower end of humeri. ${ }^{3}$ The number and location of foramina remains are non-constant feature in long bones. ${ }^{4}$ Henderson RG also reported that their location in mammalian bones are variable and may alter during the growth. ${ }^{5}$ Knowledge of the number and location of nutrient foramina is useful in certain surgical procedures. ${ }^{6}$ Though studies on the vascularisation of long bones of various populations were conducted analysing the nutrient foramina morphometric and the vascular anatomy in reconstructive surgeries, $7-10$ "the nutrient foramina of humeri were rarely studied among South Indian population. Therefore, the aim of this study was to study the precise anatomy of nutrient foramina in adult human humeri of South Indian subjects. This knowledge was of tremendous significance to orthopaedic surgeons performing procedures involving bone grafts, fracture repair, joint replacement and vascularized bone microsurgery. The long bones have four sets arterial system nutrient artery, ${ }^{10}$ epiphyseal, metaphyseal and periosteal arteries. Out of them nutrient artery play an important role during active growth period as well as in healing of fractured bones. Humerus is the long bone and it's having metaphysis, diaphysis, and epiphysis. The elongated central part ${ }^{11}$ of the humerus long bone is called the diaphysis. The enlarged area of the humerus bone at the ends is called the epiphysis and the intermediate bone segment between the two is called the Metaphysis. The articular ends of the epiphyseal surface are covered by articular cartilage. The rest of the humerus bone is covered by tough connective tissue called the periosteum. The nutrient foramen is an oblique canal usually situated in the diaphysis of the humerus long bone. The nutrient artery supplies directly from major systemic arteries. It enters the long bone through the nutrient foramen. It then divides into ascending and descending branches. These branches give of smaller parallel arteries called the radial branches. These branches supply the bone marrow and inner third of the compact bone ${ }^{12}$ of the diaphysis. The ascending and descending branches at the metaphysis divides into smaller spiral branches which anastomoses with the metaphyseal and epiphyseal arteries.

Epiphyseal arteries are derived from periarticular vascular arcades. The epiphysis has openings that allows arteries to go in and out. In children the epiphyseal arteries are separated from the metaphyseal arteries due to the presence of an epiphyseal plate. In adults the epiphysis and metaphysis is fused together following the arrest of growth plate. Here the epiphyseal arteries freely anastomose with metaphyseal and nutrient arteries. When epiphyseal cartilage and articular cartilage are continuous, the epiphyseal artery pierces the epiphyseal cartilage and supplies the epiphysis. If these arteries are damaged in epiphyseal separation, avascular necrosis may occur. In other bones where the epiphyseal cartilage is not continuous with the articular cartilage, the epiphyseal vessels enters the bone without piercing the growth plate. This helps in preventing avascular necrosis on epiphyseal separation. Metaphyseal arteries arising from the anastomosis around the joint enters the metaphysis at the margin of the capsule attachment. These anastomose with the spiral arteries making the metaphysic the most vascular area of the long bone. The periosteum has rich blood supply from the blood vessels that anastomose beneath the periosteum. Periosteal arteries act as a low-pressure system and penetrate bone at the sides of attachment of the facial sheath or aponeurosis. They enter the Volkmann's canal and supply roughly the outer one third of the compact bone of the diaphysis.

All bones possess foramina for the passes of the nourishing blood-vessels; these are known as the nutrient foramina. ${ }^{13}$ In long bones it is present on the shaft and in irregular bones it is found in other locations. These foramina lead to nutrient canals through which nutrient vessels entering the medullary cavity and supply bone marrow \& inner $2 / 3^{\text {rd }}$ of cortex. Their sites of entry and direction are almost constant and away from the dominant growing ends. Now a day's fracture of long bones are increasing in number due to an increase in road traffic accidents, industrial accidents, sports injuries, construction of multi-storey building and pathological fractures in osteoporotic patients. There are many complications of fracture, non-union is one of them. One of the very important reasons for non-union is loss of blood supply to the fractured bone. Damage to nutrient vessels, excessive stripping or injury to periosteum and muscle are few causes for loss of blood supply to the fracture site 4 hence nutrient artery plays an important role in fracture healing. Humerus is the largest and longest bone of the upper limb. Nutrient artery supplying the humerus is a branch of brachial artery. Detailed knowledge of the blood supply of bone will be helpful for the orthopaedic surgeon during any surgical procedure such as bone repair, bone graft, vascularized bone microsurgery to minimize the damage to nutrient artery of humerus. The present study was carried out to determine the number, direction and location of nutrient foramen of humerus.

\section{METHODS}

The observational study was conducted on 72 (36 right and 36 left) dried and cleaned humeri collected from Department of Anatomy, Kurnool Medical College, NTR University Vijayawada, Andhra Pradesh (India) from $15^{\text {th }}$ September to $31^{\text {st }}$ October 2020. All the humeri that were taken for the study were normal. Any damaged or pathologically deformed bones were excluded from the study. All the humeri were examined for side determination. Each humerus was examined in detail for the number, location and direction of nutrient foramen under proper illumination.

Osteometric board with sliding caliper, magnifying lens, scale and alpin were used for measuring these parameters. With the help of magnifying lens, the nutrient foramen was identified by the presence of a well-marked groove with 
slightly raised edge of the foramen at the commencement of the canal. Location of nutrient foramen in relation with surface and borders were identified and recorded. Direction of nutrient foramen in relation with growing end of humerus was observed and recorded by inserting an alpin. Total length of each bone and distance from proximal end of bone to each nutrient foramen was measured with the help of osteometric board and sliding caliper. The position of nutrient foramen in relation to zone was determined by calculating a Foraminal Index (FI) using the Hughes formula. ${ }^{5}$

$\mathrm{FI}=(\mathrm{DNF} \backslash \mathrm{TL}) \times 100$

Where -

- $\quad \mathrm{DNF}=$ Distance from the proximal end of the bone to the nutrient foramina.

- $\mathrm{TL}=$ Total length of the bone in millimeter.

- Total length of the each humerus was taken as the distance between the superior aspect of the head and the most distal aspect of the trochlea in millimeter.

- The position of foramina was divided into three zones according to FI as follows:

- Zone I: FI up to $33.33 \%$, the foramen was in proximal third of the bone.

- Zone II: FI from $33.33 \%$ to $66.66 \%$ the foramen was in the middle third of bone.

- Zone III: FI above $66.66 \%$, the foramen was in the distal third of bone

\section{Statistical Analysis}

All the numerical data were subjected to statistical analysis using SPSS. The observations and measurements were presented in proportions and percentages in descriptive statistics.

\section{RESULTS}

Out of 72 humeri studied, 36 were of right sided humeri and 36 were of left sided humeri. As shown in Table 1, single nutrient foramen was present in $65.62 \%{ }^{14}$ and $56.67 \%, 15$ double nutrient foramina

\begin{tabular}{|c|cccccc|}
\hline $\begin{array}{c}\text { No. of Nutrient } \\
\text { Foramina }\end{array}$ & $\begin{array}{c}\text { Right }=\mathbf{3 6} \\
\text { No. of } \\
\text { Humerii }\end{array}$ & $\%$ & $\begin{array}{c}\text { Left }=\mathbf{3 6} \\
\text { No. of } \\
\text { Humerii }\end{array}$ & $\begin{array}{c}\text { Total = 72 } \\
\text { No. of } \\
\text { Humerii }\end{array}$ & $\%$ \\
\hline 1 & 23 & 65.62 & 20 & 56.67 & 43 & 61.29 \\
2 & 13 & 34.37 & 11 & 26.67 & 24 & 30.65 \\
\hline 3 & 0 & & 5 & 16.66 & 5 & 8.06 \\
\hline Table 1. Number of Nutrient Foramen on Humerus \\
\hline
\end{tabular}

\begin{tabular}{|cc|ccccc|}
\hline $\begin{array}{c}\text { Location of Nutrient } \\
\text { Foramen }\end{array}$ & $\begin{array}{c}\text { Right =43 } \\
\text { No. of } \\
\text { Nutrient } \\
\text { Foramina }\end{array}$ & \% & $\begin{array}{c}\text { Left = 48 } \\
\text { No. of } \\
\text { Nutrient } \\
\text { Foramina }\end{array}$ & $\begin{array}{c}\text { Total= 91 } \\
\text { No. of } \\
\text { Nutrient } \\
\text { Foramina }\end{array}$ & $\%$ \\
\hline Anteromedial surface & 24 & 55.81 & 26 & 54.16 & 50 & 54.95 \\
Anterolateral surface & 4 & 9.3 & 7 & 14.58 & 11 & 12.08 \\
\hline Posterior surface & 6 & 13.95 & 5 & 10.42 & 11 & 12.08 \\
Medial border & 8 & 18.6 & 10 & 20.83 & 18 & 19.78 \\
\hline Lateral border & 1 & 2.32 & 0 & 0 & 1 & 1.09 \\
\hline \multicolumn{6}{|c|}{ Table 2. Location of Nutrient Foramen on Humerus } \\
\hline
\end{tabular}

were in $34.37 \% 10$ and $26.67 \%{ }^{7}$ of right and left humeri respectively and the triple nutrient foramina were found in $16.66 \%,{ }^{4}$ of left humeri and no triple foramina were found in right humeri. From the table it was concluded that the number of nutrient foramina in humerus is variable. The percentage of the bones having one nutrient foramen is $61.29 \%$, two foramina are $30.65 \%$ and three foramina are $8.06 \% .4$

\begin{tabular}{|ccc|}
\hline Zone & Number of Nutrient Foramina & $\%$ \\
Zone I & 2 & 2.19 \\
Zone II & 86 & 94.5 \\
Zone III & 3 & 3.3 \\
\hline \multicolumn{3}{|c|}{ Table 3. Location of Nutrient Foramen } \\
& with Regard to Zone of Humerus. \\
\hline
\end{tabular}

From the above table, it was concluded that the majority $(54.95 \%)$ of the nutrient foramina were located on the anteromedial surface of the shaft of humeri. Next in the order are medial border (19.78\%), anterolateral surface (12.08\%), and posterior surface $(12.08 \%)$ and lateral border $(1.09 \%)$.

Majority of nutrient foramen, $94.5 \%$ (86) were present in middle one-third or zone II of shaft of humeri, followed by lower one-third or zone III, $3.3 \%^{1}$ and by upper one-third or zone I, $2.19 \%$.

It was observed that all the nutrient foramina were directed towards the elbow joint i.e. away from the growing end.

\section{DISCUSSION}

In spite of optimal treatment, some fracture either heal slowly or do not heal. One of the important causes of non-healing or delayed healing is lack of arterial supply. Nutrient artery which is a richest source of blood supply enters in the medullary cavity through nutrient foramen. The knowledge of variations of nutrient foramina will be helpful for orthopaedic surgeons to avoid injury to the nutrient artery while performing an open reduction of a fracture and thus lessening the chances of delayed or non-union of the fracture.

From this study it is observed that $61.29 \%$ of humeri have single nutrient foramen. A similar finding $60.87 \%$ was observed by Mansur DI et al. in Nepalese subjects.' Almost similar finding (60\%) was observed by Shaheen in Saudi Arabia. Mysorekar et al. (58 \%) in Indian population and Joshi et al. (63\%) among Gujarati population. Many studies reported high percentage of incidence of single foramina. A study done by Khan AS et al. on 75 humerus reported that 90 $\%$ of humeri had single nutrient foramen.' A similar study done by Caroll et al. in 71 humeri collected from University of Western Ontario, London observed that $67.61 \%$ of humeri had a single nutrient foramen.' A study conducted by Forriol et al. in 36 humeri collected from Medical School of Alcala de Henares University found that $75 \%$ of humeri had single nutrient foramen as compared to the present study. Similarly, a study conducted by Peirera et al. reported the incidence of $88.5 \%$ of humeri having single nutrient foramen in Southern Brazil and Bhatnagar et al. reported the incidence of $90 \%$ in Uttar Pradesh (India).

The present study showed that $30.65 \%$ of humeri have double nutrient foramen which was similar to the findings observed by Mansur DI in Nepal who reported 28.85 \%', Carroll in London reported $28.16 \%$ of humeri', Joshi et al. reported $33 \%$ and Shaheen reported $33.3 \%$. Similar studies conducted by Bhatnagar et al. reported a lower incidence of 
$7.14 \%$ of humeri having double nutrient foramen, Halagatti et al. reported (17.5\%) and Solanke et al. reported (4\%).

The present study observed $8.06 \%$ of humeri having triple nutrient foramina which were nearly similar to the studies conducted by Shaheen (6.7 \%) in Saudi Arabia and Mansur DI et al. (6.32 \%) in Nepal'. Whereas findings reported by Bhatnagar et aI. (1.42\%), Halagatti (2\%) and Yaseen et al. (2 $\%)$ was comparatively lesser than the finding observed in the present study. The nutrient foramina are situated a little below its midpoint on the anteromedial surface close to the medial border of humeri. However; the location of foramina may vary in position. In present study $54.95 \%$ of foramina were present on anteromedial surface of humeri.

From the present study it is observed that the majority of nutrient foramina $(94.50 \%)$ were present in zone II (the middle one-third) diaphysis of the shaft of the humeri which was correlated with the study conducted by Mansur DI et al. who reported $94.84 \%, 5$ Khan et al. reported $96.20 \%$ of nutrient foramina on the middle one-third of humeri in Pakistan cadavers. ${ }^{16}$ A study conducted by Ukoha et al. in humeri of Nigerian population found that $100 \%$ of the nutrient foramina were located on the middle one-third of the humeri and a similar trend also reported by Kumar et al. (100 $\%)$ in Indian population which was higher than the present result. $12^{\circ}$ However, Halagatti et al. noticed lower (84\%) incidence of nutrient foramina in the middle one-third of the shaft of humeri. The direction of the nutrient foramina was directed horizontally before birth but as the growth proceeds the direction of nutrient foramina were directed away from the growing end of the humeri.' The present study showed that the direction of all the nutrient foramina of humeri was directed towards the lower end of humeri which was supported by many other studies, ${ }^{17}$ which revealed that the direction of nutrient foramina was constant and obeys the law of ossification. Similarly, Kumar et al. reported that the direction of all nutrient foramina present in the humeri were directed away ${ }^{18}$ from the growing end of humeri except one which was directed towards the upper end. ${ }^{19}$ Similarly, Khan et al. also observed that $98.67 \%$ of the nutrient foramina were directed distally towards the lower end of humeri which was in accordance with the present result.

\section{CONCLUSIONS}

Majority of humerii have single nutrient foramen and they are mainly located on the anteromedial surface especially in zone II (the middle one-third). The direction of all the foramina is constant and away from the growing end. Knowledge with regard to location of the nutrient foramina and their variation will be helpful for orthopaedic surgeon to decrease the chances of damaging the nutrient artery during open or close procedures. As damage to the nutrient artery may cause delayed union or non-union ${ }^{20}$ following fracture of shaft of humerus. It will also help in avoiding this area during surgical procedures like bone repair, bone graft, micro vascular bone surgery, and during extensive stripping of the periosteum so that they can minimise the damage to the nutrient artery of humerii.
Data sharing statement provided by the authors is available with the full text of this article at jemds.com.

Financial or other competing interests: None.

Disclosure forms provided by the authors are available with the full text of this article at jemds.com.

\section{REFERENCES}

[1] Longia GS, Ajmani ML, Saxena SK, et al. Study of diaphyseal nutrient foramina in human long bones. Acta Anat (Basel) 1980;107(4):399-406.

[2] Sendemir E, Cimen A. Nutrient foramina in the shafts of lower limb long bones: situation and number. Surg Radiol Anat 1991;13(2):105-8.

[3] Standring S. Gray's Anatomy. 40th edn. Churchill Livingstone/ Elsevier 2008: p. 798.

[4] Bokariya P, Gudadhe D, Kothari R, et al. Comparison of humerus and femur with respect to location and number of nutrient foramina. Indian Journal of Forensic Medicine and Pathology 2012;5(2):79-81.

[5] Henderson RG. The position of the nutrient foramen in the growing tibia and femur of the rat. J Anat 1978;125(Pt 3):593-9.

[6] Mysorekar VR. Diaphysial nutrient foramina in human long bones. J Anat 1967;101(Pt 4):813-22.

[7] Nagel A. The clinical significance of the nutrient artery. Orthop Rev 1993;22(5):557-61.

[8] Dyankova S. Vascular anatomy of the radius and ulna diaphyses in their reconstructive surgery. Acta Chir Plast 2004;46(4):105-9.

[9] Choi SW, Kim HJ, Koh KS, et al. Topographical anatomy of the bula and peroneal artery in Koreans. Int J Oral Maxillofac Surg 2001;30(4):329-32.

[10] Schiessel A, Zweymuller K. The nutrient artery canal of the femur: a radiological study in patients with primary total hip replacement. Skeletal Radiol 2004;33(3):142-9.

[11] Shaheen SY. Diaphyseal nutrient foramina in human upper and lower limb long bones. A thesis submitted for the partial fulfillment of the requirement for the Master Degree in Anatomy 2009:20-1.

[12] Joshi H, Doshi B, Malukar O. A study of the nutrient foramina of the humeral diaphysis. National Journal of Integrated Research in Medicine 2011;2(2):14-7.

[13] Asharani SK, Ningaiah A. A study on the nutrient foramen of humerus. Int J Anat Res 2016;4(3):2706-9.

[14] Carroll SE. A study of the nutrient foramina of the humeral diaphysis. J Bone Joint Surg 1963;45-B:176-81.

[15] Mansur DI, Manandhar P, Haque Mk, et al. A study on variations of nutrient foramen of humerus with its clinical implications. Kathmandu Univ Med J (KUMJ) 2016;14(53):78-83.

[16] Khan AS, Shah Z, Qasier I. Anatomical variations in diaphyseal nutrient foramina of humerus in cadavers from khyber pakhtunkhwa, Pakistan. Khyber Med Univ J 2014;6(1):18-21.

[17] Bharathi A, Janaki V, Gouri TLS, et al. Morphometric variations of nutrient foramen in adult human humerus in Telangana region. Journal of Dental and Medical Sciences 2016;15(4):43-6.

[18] Hughes $\mathrm{H}$. The factors determining the direction of canal for the nutrient artery in the long bones of mammals and birds. Acta Anat (Basel) 1952;15(3):261-80. 
[19] Datta AK. The sclerous tissue. In: Principles of General Anatomy. $6^{\text {th }}$ edn. Kolkata: K.P. Basu Publishing Co 2007:75-6.
[20] Kulkarni GS, Limaye R. Non-union of fractures of long bones. Orthopedics and Trauma. $1^{\text {st }}$ edn. New Delhi: Jaypee Brothers Medical Publishers 1999;2:1542-4. 